\title{
Fast free of acrylamide clearing tissue (FACT) for clearing, immunolabelling and three-dimensional imaging of partridge tissues
}

\author{
Farzad Mohammad Rezazadeh $^{1^{*}}$ | Saman Saedi ${ }^{1^{*}}$ | Farhad Rahmanifar ${ }^{2 *}$ | \\ Mohammad Reza Namavar ${ }^{3}$ | Mehdi Dianatpour ${ }^{4,5}$ | Nader Tanideh ${ }^{4,6}$ | \\ Amir Akhlaghi $^{1}$ | Ali Niazi ${ }^{7}$ | Ali Arabi Monfared ${ }^{8}$ | Kazuyoshi Tsutsuii ${ }^{9}$ | \\ Mohammad Reza Jafarzadeh Shirazi ${ }^{1}$ | Amin Tamadon ${ }^{10}$
}

\footnotetext{
${ }^{1}$ Department of Animal Science, College of Agriculture, Shiraz University, Shiraz, Iran

${ }^{2}$ Department of Basic Sciences, School of Veterinary Medicine, Shiraz University, Shiraz, Iran

${ }^{3}$ Clinical Neurology Research Center, and Histomorphometry \& Stereology Research Center, Shiraz University of Medical Sciences, Shiraz, Iran

${ }^{4}$ Stem Cells Technology Research Center, Shiraz University of Medical Sciences, Shiraz, Iran

${ }^{5}$ Department of Medical Genetics, School of Pharmacy, Shiraz University of Medical Sciences, Shiraz, Iran

${ }^{6}$ Department of Pharmacology, School of Medicine, Shiraz University of Medical Sciences, Shiraz, Iran

${ }^{7}$ Institute of Biotechnology, Shiraz University, Shiraz, Iran

${ }^{8}$ Central Research Laboratory, Shiraz University of Medical Sciences, Shiraz, Iran

${ }^{9}$ Department of Biology, Waseda University, Shinjuku-ku, Tokyo, 162-8480, Japan

${ }^{10}$ The Persian Gulf Marine Biotechnology Research Center, The Persian Gulf Biomedical Sciences Research Institute, Bushehr University of Medical Sciences, Bushehr, Iran
}

\section{Correspondence}

Amin Tamadon, The Persian Gulf Marine Biotechnology Research Center, The Persian Gulf Biomedical Sciences Research Institute, Bushehr University of Medical Sciences, Bushehr, Iran; Postal Code: 7514633196; Tel/ fax:+98-77-3332-8724

Email: amintamaddon@yahoo.com and

Mohammad Reza Jafarzadeh Shirazi, Department of Animal Science, College of Agriculture, Shiraz University, Shiraz, Iran.

Email: jafarzd@shirazu.ac.ir

Funding information

Department of Animal Science, College of Agriculture, Shiraz University

\begin{abstract}
Fast free of acrylamide clearing tissue (FACT) is a modified sodium dodecyl sulfate-based clearing protocol for the chemical clearing of lipids that completely preserves fluorescent signals in the cleared tissues. The FACT protocol was optimized to image translucent immunostained brain and non-nervous tissues. For this purpose adult male Chukar partridge (Alectoris chukar) was used as a model. After clearing the tissues, 1 or 2 mm-thickness sections of tissues were immunolabeled. The paraventricular nucleus in the hypothalamus (2-mm section) was cleared with FACT, and then was stained with gonadotropin-inhibitory hormone $(\mathrm{GnlH})$ antibody and Hoechst. Simultaneously, immunohistochemical (IHC) staining of cryosectioned brain $(30 \mu \mathrm{m})$ was done by $\mathrm{GnlH}$-antibody. The FACT protocol and staining of cell nuclei of nine other tissues were done by a z-stack motorized fluorescent microscope. GnIH-immunoreactive neurons were found by FACT and IHC during the breeding season in male partridges. Deep imaging of the kidney, duodenum, jejunum, lung, pancreas, esophagus, skeletal muscle, trachea, and testis were also done. The FACT protocol can be used for the three-dimensional imaging of various tissues and immunostained evaluation of protein markers.

\section{Research highlight}

- The FACT is a simple and cheap method for whole tissue clearing.

- The FACT-cleared tissues can be imaged with simple fluorescent microscopes.

- For the first time, using the FACT, three-dimensional imaging of various tissues was done.
\end{abstract}

*These authors have same contribution as first authors. 


\section{KEYWORDS}

Chukar partridge, FACT, GnIH, paraventricular nucleus, three-dimensional imaging

\section{1 | INTRODUCTION}

Three-dimensional (3D) imaging can authorize the study of systems from various cellular and extracellular structures, such as cellular behavior in developing embryos and neuronal networks in brain (Dodt et al., 2007; Tomer, Ye, Hsueh, \& Deisseroth, 2014). Therefore, such studies require an extremely transparent tissue for detection. The fact that lipids are a main factor of light scattering in the tissues, the removal of them is a potential approach for increasing tissues transparency. Several techniques of lipid removing transparency have been developed for 3D imaging of tissues, including CLARITY (Chung et al., 2013), passive CLARITY (Tomer et al., 2014), PACT (Yang et al., 2014), PARS (Yang et al., 2014), SWITCH (Murray et al., 2015), FASTClear (Liu, Lai, Chang, \& Gentleman, 2017), and FACT (Xu et al., 2017).

Some of these techniques that clear tissue transparent and use hydrogel including CLARITY and PACT are not only costly, but also change tissue volume, require several days to weeks to completely clear the tissue, disrupt the fluorescent signal of immunohistochemistry $(\mathrm{IHC})$, and finally cannot prevent the quenching of fluorescent protein signals for a long time. These hydrogel based technique also need to a well-equipped laboratory. Therefore, a simple technique can be appropriate for laboratories in developing countries that lack advanced microscopes, such as confocal microscope. One of these newly-developed simple techniques is the FACT (fast free of acrylamide clearing tissue) technique (Xu et al., 2017).

Conversely, the identification of novel neuropeptides that play important roles in the regulation of pituitary functions is fundamental in the fields of neurosciences, such as neuroendocrinology and neurobiology. One of these neuropeptides is gonadotropin-inhibitory hormone $(\mathrm{GnlH})$. GnlH is a hypothalamic neuropeptide that is expresses in the paraventricular nucleus (PVN) and inhibits gonadotropins secretion from the pituitary in the avian species Japanese quail (Tsutsui et al., 2000). By the follow-up studies, it now appears that GnlH can be an important regulator of reproductive functions in birds (Tsutsui, Ubuka, Bentley, \& Kriegsfeld, 2013). Our previous results with IHC method showed compacted populations of $\mathrm{GnlH}$-ir neurons in the PVN of male partridges (Rezazadeh et al., 2017). GnlH and its mammalian orthologue, RF amide related peptide (RFRP)(Salehi et al., 2015), have role in different reproductive and physiological conditions including spermatogenesis (Karami Kheirabad et al., 2016), pregnancy (Sarvestani et al., 2014), lactation (Adavi et al., 2011; Asadi Yousefabad et al., 2013; Noroozi, Jafarzadeh Shirazi, Tamadon, Moghadam, \& Niazi, 2015), estrus cycle (Jafarzadeh Shirazi, Namavar, \& Tamadon, 2011a, 2011b, 2011c; Jafarzadeh Shirazi et al., 2013; Salehi et al., 2013), malnutrition condition (Jahanara et al., 2014), seasonal breeding (Jafarzadeh Shirazi et al., 2014; Rezazadeh et al., 2017), and ovarian diseases (Shaaban et al., 2018).

The traditional method of tissue evaluation using the twodimensional (2D) imaging does not provide a comprehensive picture of cellular reactions to intercellular interactions between cells in three dimensions. Therefore, novel methods are urgently needed for the simultaneous evaluation of neurons in the 3D imaging, with a focus on fine details of their structural contacts with surrounding neurons. Given that the FACT protocol can be used for deep tissue imaging, and also considering the speed of processing, and preservation of cytoarchitecture (Xu et al., 2017), here we have systematically simplified FACT and compared it with the IHC method. This study has also evaluated the FACT protocol for whole tissue clearing of several types of tissues in partridges.

\section{2 | MATERIALS AND METHODS}

\section{1 | Birds}

Adult (1.5 to 2 years-old) male Chukar partridges were used and kept in Animal Research Station of the College of Agriculture, Shiraz University. The birds were housed in outdoor cages under natural photoperiods and had free access to feed and water. All procedures were performed in accordance to the Shiraz University Guidelines for Animal Handling, and the project was performed according the instruction of working on laboratory animal of the Ethics Committee of Shiraz University.

\section{2 | FACT protocol}

The birds were anesthetized with chloroform and perfused with $500 \mathrm{~mL}$ phosphate-buffered saline (PBS) solution (0.01 M, pH 7.5). Through the left cardiac ventricle, the birds were then perfused with $500 \mathrm{~mL}$ 4\% paraformaldehyde (PFA) diluted in PBS solution (0.01 M)

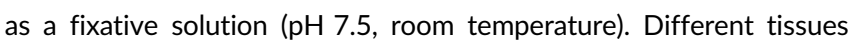
including, the brain, kidney, duodenum, jejunum, lung, pancreas, esophagus, skeletal muscle, trachea, and testis were dissected out. Tissues were postfixed in the same fixative solution at $4{ }^{\circ} \mathrm{C}$ for 3 days. The brain was $2 \mathrm{~mm}$-sliced coronally using a rat brain slicer matrix. Then the tissues were cleared with $8 \%$ (wt/vol) sodium dodecyl sulfate (SDS) in $0.01 \mathrm{M} \mathrm{PBS} \mathrm{(pH} \mathrm{7.5)} \mathrm{that} \mathrm{was} \mathrm{supplemented} \mathrm{with} 0.02 \%$ sodium azide, at $37{ }^{\circ} \mathrm{C}$ with mild rotational horizontal shaking (100 r/ $\min )$. The solutions were refreshed daily for 3 days, and then were refreshed weekly until visual confirmation of $80 \%$ tissue transparency by viewing black grid lines on a white sheet of the paper through the tissue itself.

\section{3 | GnIH staining of FACT-cleared hypothalamus}

Fluorescent immunostaining was done on the brain of Chukar partridge. After clearing of brain slices with FACT protocol, the SDS was removed by washing in PBS supplemented with $0.02 \%$ sodium azide for $24 \mathrm{hr}$ in mild rotational shaking. For saving antibody consumption, 


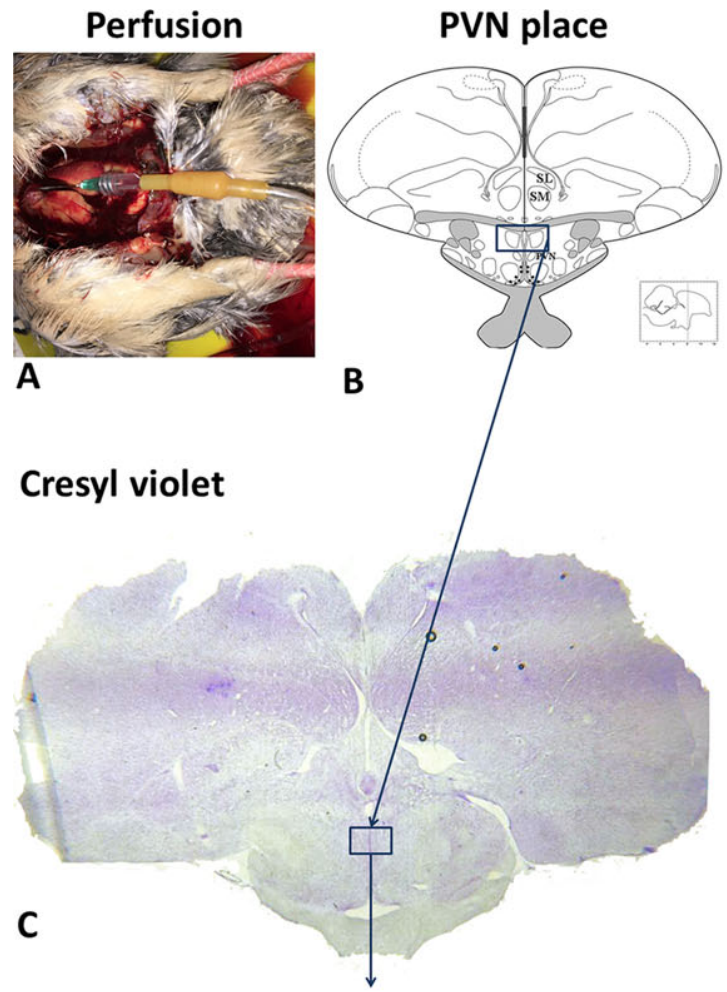

\section{Immunohistochemistry}

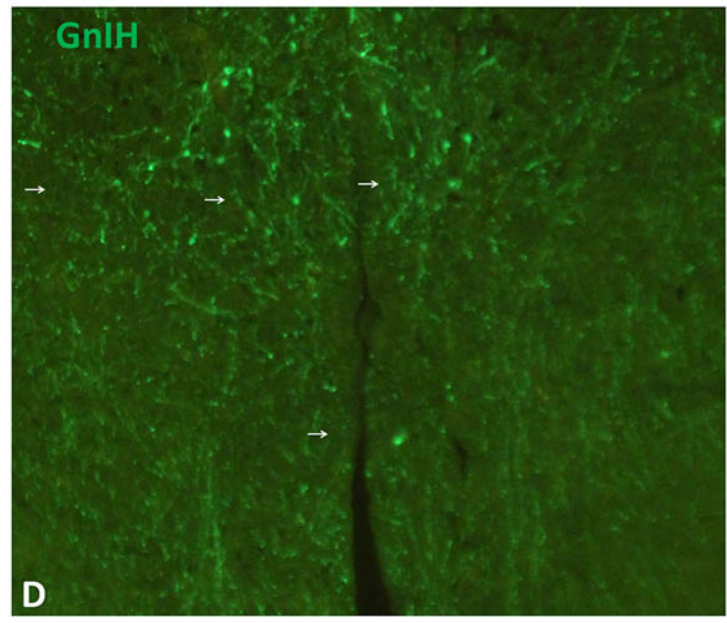

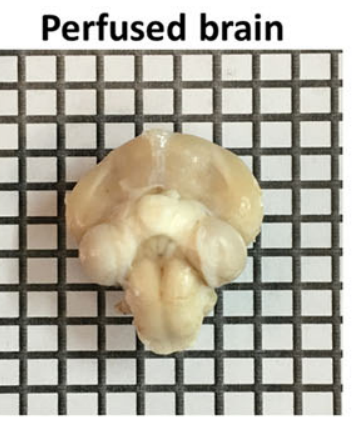

Day 2

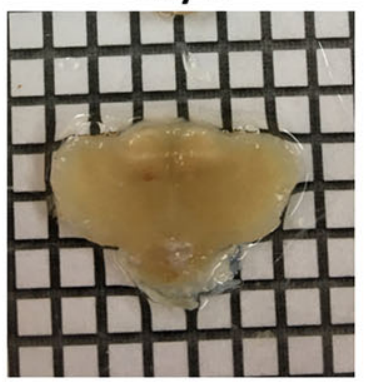

$\mathbf{E}$

\section{D imaging by FACT}

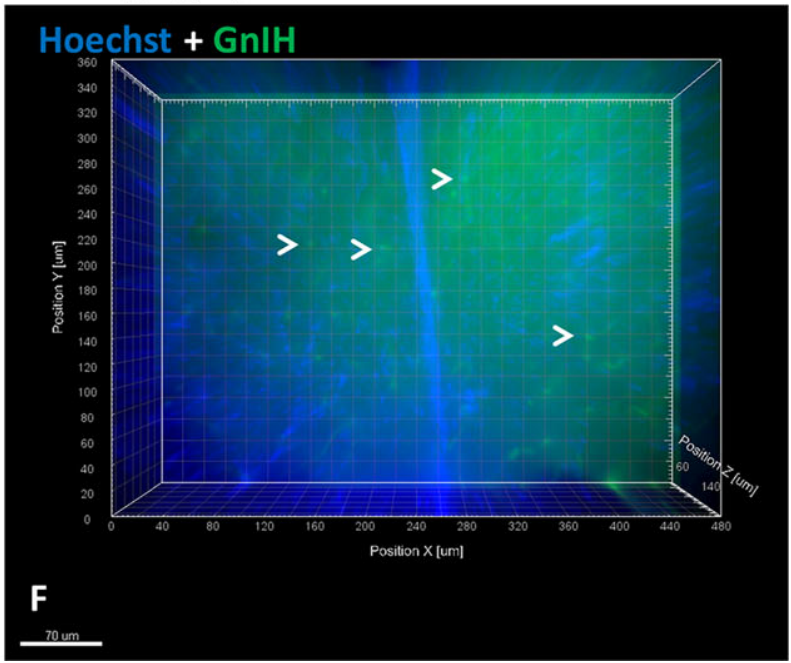

FIGURE 1 Comparison of immunohistochemistry (IHC) and fast free of acrylamide clearing tissue (FACT) for labeling of gonadotropin-inhibitory hormone $(\mathrm{GnIH})$ in the paraventricular nucleus $(\mathrm{PVN})$ in the partridge hypothalamus. (A) Cardiac perfusion of the partridge. (B) Schematic drawing of region of the PVN in the chicken hypothalamus (Kuenzel, 2015). (C) Cresyl violet staining of brain coronal section of the partridge contains the PVN. (D) GnlH in neuronal cell bodies (arrows) in the PVN of the male partridge during the breeding season, which are presented by immunohistochemistry (IHC). (E) Ventral view of whole brain of the partridge is perfused with $4 \%$ paraformaldehyde (squares are $3 \times 3 \mathrm{~mm}^{2}$ ) and 2-mm coronal sectioned brain contains the PVN 1, 2, and 3 days after clearing with the FACT method. The lines are visible through the tissue after 3 days. (F) Three-dimensional (3D) image of the partridge PVN by the FACT clearing protocol. Expression of GnIH in neuronal cells (arrows) in the male partridge during breeding season. Hypothalamic cells' nuclei were stained with Hoechst 33342 [Color figure can be viewed at wileyonlinelibrary.com]

slices containing the PVN was selected (Figure 1) according to chicken brain atlas (Kuenzel, 2015). Then, the hypothalamic part containing the PVN was trimmed by removing surrounding parts. The hypothalamus part was incubated in the primary antibody (rabbit anti-quail GnlH antibody at 1:500) in PBS solution in a shaker for 2 days at $37{ }^{\circ} \mathrm{C}$. The antibody against quail $\mathrm{GnIH}$ (gifted by professor Tsutsui, Waseda University, Tokyo, Japan) cross reacts with the fragment of various vertebrate $\mathrm{GnIH}$, such as quail (Tsutsui et al., 2000), chicken (Chowdhury et al., 2012) and goat (Jafarzadeh Shirazi et al., 2014).
After $24 \mathrm{hr}$ washing in PBS supplemented with $0.02 \%$ sodium azide, the hypothalamic piece was subsequently incubated with the FITClabeled goat anti-rabbit immunoglobulin G (Invitrogen, Carlsbad, CA, USA; 1:100 in the blocking solution) for $48 \mathrm{hr}$ in aluminum foilcovered tubes in a shaker at $37{ }^{\circ} \mathrm{C}$. Both the primary and secondary antibodies were diluted in PBS supplemented with $0.02 \%$ sodium azide. Following, $36 \mathrm{hr}$ in FITC, Hoechst 33342 (1:200) was added to the secondary antibody solution and incubated in shaker incubator $37^{\circ} \mathrm{C}$ for remaining $12 \mathrm{hr}$ (Hoechst 33342 was used for the cell 
nuclear staining). Then, the hypothalamic piece was washed 2 times in PBS supplemented with $0.02 \%$ sodium azide, and then was shaken gently $12 \mathrm{hr}$ in the same solution at $37^{\circ} \mathrm{C}$ in aluminum foil-covered tubes. For complete transparency, hypothalamic piece was placed in $80 \%$ glycerol for $12 \mathrm{hr}$ in room temperature prior to imaging.

\subsection{Nuclear staining of FACT-cleared tissues}

To confirm adaptability of the FACT method for immunolabelling of different type of tissues, the nuclear staining was performed on 9 types of cleared tissues. The SDS was removed by washing in PBS (0.01 M) supplemented with $0.02 \%$ sodium azide for $24 \mathrm{hr}$ at $37^{\circ} \mathrm{C}$ with mild rotational horizontal shaking $(100 \mathrm{r} / \mathrm{min})$. For imaging the tissues under a fluorescent microscope (size limitation), tissues were cut after transparency with 1-mm thickness using a razor blade. Then, the sections were labeled with Hoechst 33342 (1:200) in PBS supplemented with $0.02 \%$ sodium azide and tubes were covered by aluminum foil and placed in a shaker at $37^{\circ} \mathrm{C}$ for $12 \mathrm{hr}$. The tissue sections were washed in PBS supplemented with $0.02 \%$ sodium azide for $24 \mathrm{hr}$, two times each $12 \mathrm{hr}$ in a shaker at $37^{\circ} \mathrm{C}$. Then, the sections placed in $80 \%$ glycerol for $12 \mathrm{hr}$ in room temperature prior to imaging for refractive index homogenization.

\section{5 | Immunohistochemical (IHC) staining of GnIH neurons}

The PVN in the hypothalamus is the only source of $\mathrm{GnIH}$ synthesis in the avian brain (Tsutsui et al., 2010). After dissecting out the perfused brains, each brain was coronally sectioned $(30 \mu \mathrm{m})$ using frozen microtome. The appropriate slices for IHC were identified using a chicken brain atlas (Kuenzel, 2015). To confirm the similarity of partridge and chicken brains, all sections from the third well were mounted on a slide and stained with cresyl violet. All sections for IHC were postfixed for 10 to $20 \mathrm{~min}$ in $4 \%$ paraformaldehyde and washed with PBS for three times. Afterward, they were incubated in a blocking solution (1\% normal goat serum, $1 \%$ bovine serum albumin (BSA), $0.3 \%$ Triton $\mathrm{X}-100$ in PBS) for $30 \mathrm{~min}$. The sections were then incubated with the rabbit anti-quail GnIH antibody (1:5,000 in blocking solution) overnight at $4{ }^{\circ} \mathrm{C}$ and washed with PBS for three times. The sections were subsequently incubated with the FITC-labeled goat anti-rabbit immunoglobulin G (Invitrogen, Carlsbad, CA; 1:500 in the blocking solution) for $60 \mathrm{~min}$ in a dark environment. Eventually, the sections were washed with PBS and covered with Dako fluorescence mounting medium (Dako, Glostrup, Denmark).

\subsection{D and 3D fluorescent microscopies}

For the 2D fluorescent microscopy, immunoreactive (-ir) GnlH neurons were imaged in the PVN using a fluorescent microscope (Nikon, Japan). For the 3D imaging, tissues were individually mounted between 2 glass slides and using noncolorful putty that formed a horse-shoe-like chamber (1- to 2-mm thickness wall) was designed to support the tissues thickness. This chamber between two slides was filled with fresh $80 \%$ glycerol. The mounted tissues were imaged by an Olympus microscope BX61 (model of U-LH100HGAPO, Tokyo, Japan), DP73 camera, and
Olympus cellSens imaging software (Version 1.13). For this purpose selected area was imaged on a z-stack manner (each $10-\mu \mathrm{m}$ step) for depth of $150 \mu \mathrm{m}$ from tissue surface, automatically.

\section{7 | 3D image preparation}

After obtaining the images, the TIFF image sequences were transferred to Imaris software (version 7.4.2, ImarisX64, Bitplane AG) for the $3 \mathrm{D}$ reconstruction. Because the large amount of data, a workstation server was used for the image 3D reconstruction.

\section{8 | Hematoxylin and eosin staining of cleared and noncleared tissues}

To evaluate the effect of FACT protocol on classical histology we stained cleared and noncleared tissues with hematoxylin and eosin protocol. This part of study showed the effect of clearing procedure on tissue maintenance in classical histology and possibility of use of classical histology on previously cleared method was evaluated. Specimens were processed for cryosectioning histology and subsequent hematoxylin and eosin staining on the FACT-cleared and standard $4 \%$ (wt/v) PFA fixed specimens. In details, after clearing with the FACT, the tissue was kept in $1 \mathrm{X}$ PBS solution containing $0.02 \%$ sodium azide in $4{ }^{\circ} \mathrm{C}$. Before sectioning with cryotome, gelatinized slides were prepared. For this purpose, 3\% gelatin (Merck, Germany) in distilled water was solved in $40^{\circ} \mathrm{C}$. Slides were covered by submerging them, $5 \mathrm{~min}$ in the solution and then dried in $37^{\circ} \mathrm{C}$ incubator.

Both type of tissue samples were blocked in OCT and kept in freezer until sectioning. Using a cryostat (MEV, Slee Medical, Germany), $24 \mu \mathrm{m}$ sections of different cleared and noncleared tissues were prepared and transferred on gelatinized slides. Immediately, 99\% ethanol was dropped gently on the slices using a syringe. After air drying of ethanol, this process of dropping and drying was done by $80 \%$ ethanol, 50\% ethanol, and distilled water. After drying water, 1 drop of hematoxylin (Merck, Germany) was poured on the slice for $1.5 \mathrm{~min}$ and then was washed with distilled water in a syringe. Then, eosin (Merck, Germany) was dropped on sample $45 \mathrm{~s}$ and was washed with distilled water. Rehydration was done after drying of the slide by adding $80 \%$ ethanol and let it to dry. Then, $99 \%$ ethanol was dropped gently and it was dried by air. A drop of Entellan rapid mounting medium (Merck, Germany) was purred on the sample and covered with cover-slip. Then, the tissue slices were imaged with light microscope (CX21, Olympus, Japan) and were photographed by an adjusted digital camera (AM423U Eyepiece Camera, Dino-Eye, Taiwan) and Dino Capture 2.0 software (AnMo Electronics Corporation, New Taipei City, Taiwan).

\section{3 | RESULTS}

\section{1 | IHC staining of GnlH neurons}

Compacted populations of $\mathrm{GnlH}$-ir neurons were identified in the PVN of male Chukar partridges during the breeding season by IHC staining of GnlH neurons (Figure 1). GnlH-ir neurons were also 3D imaged and detected in the PVN of male Chukar partridges by the FACT method (Figure 1). 


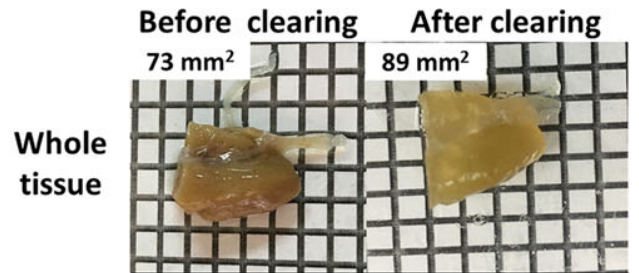

Kidney

3D

image
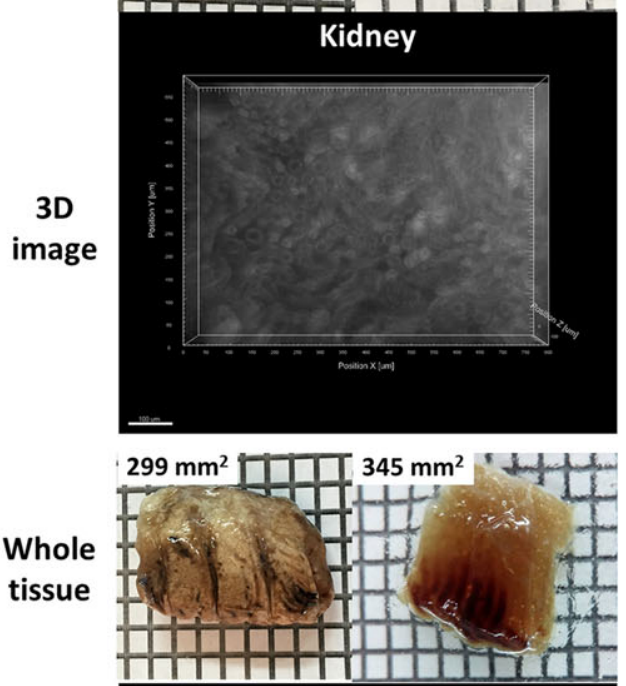

Lung

3D

image

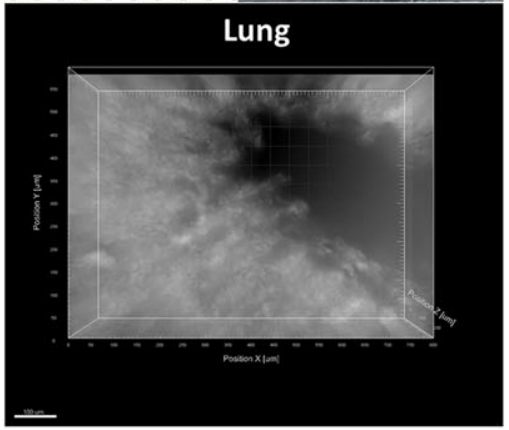

$152 \mathrm{~mm}^{2} \mathrm{H}+160 \mathrm{~mm}^{2}+\mathrm{H}$

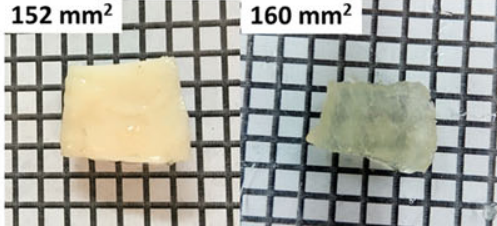

tissue

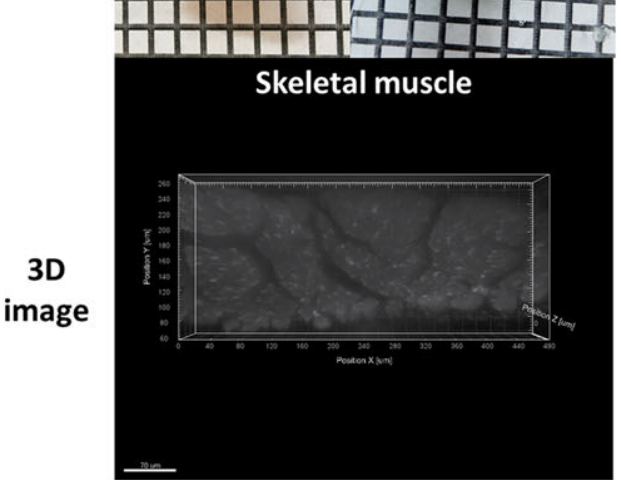

Before clearing After clearing

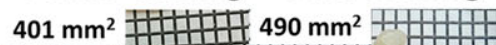

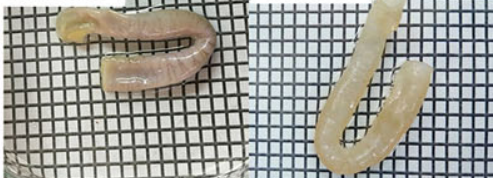

Duodenum

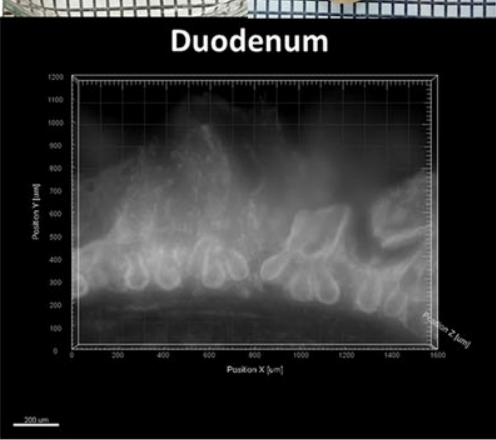

$312 \mathrm{~mm}^{2} \mathrm{H}$ (12 $\mathrm{mm}^{2}$

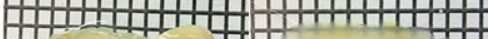

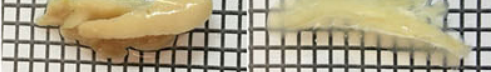

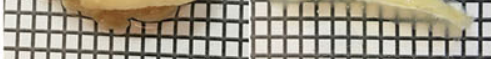

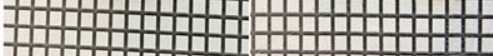

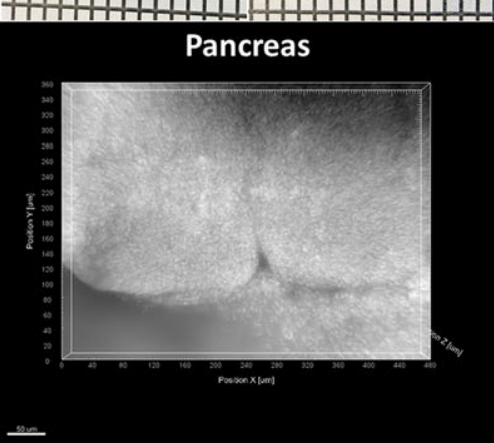

$152 \mathrm{~mm}^{2}$
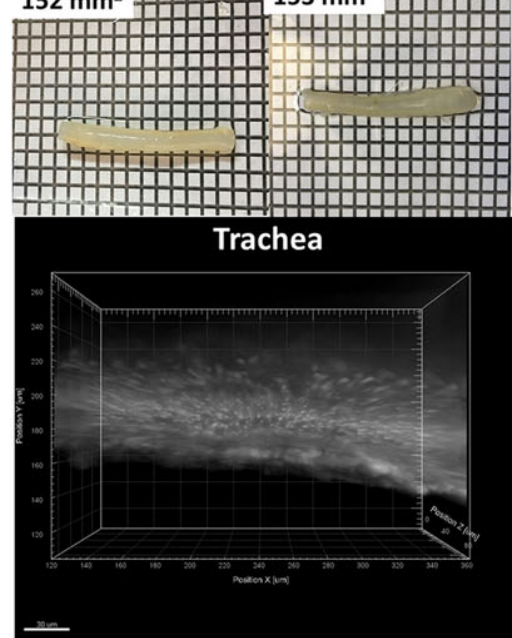

Before clearing After clearing $182 \mathrm{~mm}^{2}+268 \mathrm{~mm}^{2}$ $182 \mathrm{~m}^{2}+\mathrm{H}+\mathrm{H}$ \#

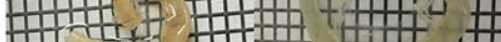
\# \# \#\#\#

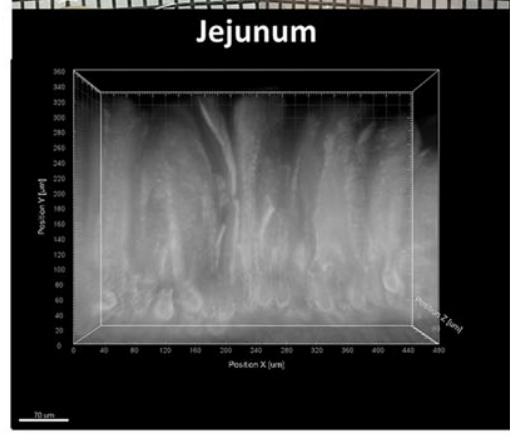

$130 \mathrm{~mm}^{2} \mathrm{\#}$

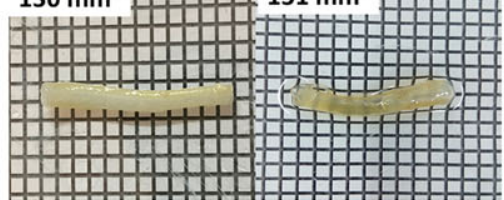

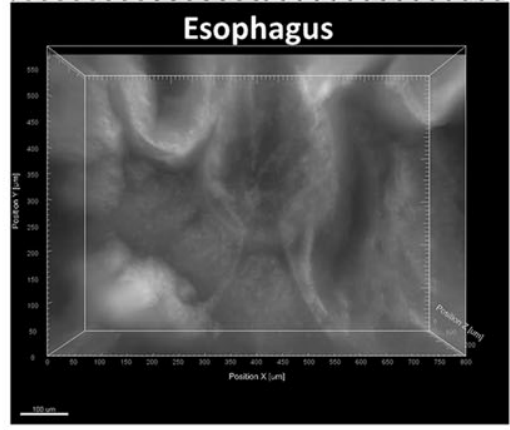

$142 \mathrm{~mm}^{2}$ TIT $193 \mathrm{~mm}^{2}$

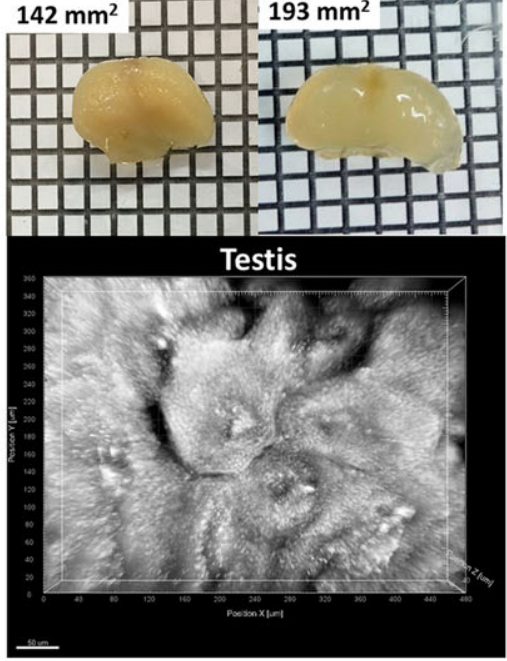

FIGURE 2 Whole tissue clearing and imaging of partridge tissues using fast free of acrylamide clearing tissue (FACT). Three-dimensional (3D) imaging of whole tissue after imaging of 1-mm thickness slices were immunolabeled with Hoechst 33342 (squares are $3 \times 3 \mathrm{~mm}^{2}$ ) [Color figure can be viewed at wileyonlinelibrary.com]

\subsection{Whole tissues clearing with FACT method}

The FACT protocol could transparent different whole tissue samples of partridges (Figure 2). In birds, kidney divides into cranial, middle, and caudal portions. In Figure 2, clearing of caudal part of partridge's kidney (ureter is visible) has been demonstrated. Increase of volume can be seen after clearing (1.2 times). The 3D image shows the 3D structure of distal convoluted tubules and proximal convoluted tubules in partridge kidney. 
In Figure 2, duodenum of partridge was cleared with the FACT and increase in tissue area can be seen (1.2 times). The 3D image of duodenum demonstrates lamina properia and clearly shows 3D structure of thick villi. Above the muscularis mucosa and at the end of the villi, several crypts of Lieberkuhn are visible as poaches.

Clearing of jejunum of partridge with the FACT increased tissue area (1.5 times). The 3D image of jejunum represented lamina properia containing 3D structure of long and compacted villi and crypts (Figure 2).

As the perfusion of partridges was done through general blood circulation, blood cells were not removed from lungs. Therefore, after whole tissue clearing with FACT, presence of hemoglobin in blood vessels and capillaries are visible. Expansion of lung after clearing was the same as other tissues (1.2 times). In 3D image of lung, a parabronchus has been imaged. In the border spaces which call atria are visible.

Partridge pancreas contains dorsal, ventral, third and splenic lobes that are visible before and after clearing (1.1 times expansion in area). Exocrine portion 3D structure has been shown in Figure 2.

Esophagus of partridge was cleared without expansion. In 3D image, different layers of esophagus have been seen from top to bottom: stratified squamous epithelium, lamina properia, submucosa, and muscularis externa (Figure 2).

A skeletal muscle piece $\left(1 \mathrm{~cm}^{3}\right)$ that was cleared with the FACT was not considerably expanded (1.1 times). In 3D image, transversally cut muscle fibers and the skeletal muscle cell nuclei are visible in Figure 2 .

Trachea of partridge was cleared without expansion. In 3D image, respectively from bottom of picture to top, trachea lumen (bottom), pseudostratified ciliated columnar epithelium, hyaline cartilage (cartilage cells nuclei are clearly seen) are imaged.

In Figure 2, a testis of partridge was cleared with the FACT and increase in tissue area is considerable comparing with other tissue (1.4 times). In 3D image, seminiferous tubules and stained nuclei of spermatogenesis layers are visible (Figure 2).

We further demonstrated the versatility of the FACT method for clearing of nervous and non-nervous tissues. Table 1 shows transparency timing of partridge tissues with the FACT. Additionally, the tissues' structures were visible as deep as $200 \mu \mathrm{m}$ in the cleared tissues.

TABLE 1 Clearing time of partridge whole or sectioned tissue with fast free of acrylamide clearing tissue (FACT) method

\begin{tabular}{|ll|}
\hline Tissue & Clearing time (days) \\
\hline Brain slice (2-mm coronal section) & 3 \\
\hline Kidney (whole size) & 35 \\
\hline Duodenum (whole size) & 26 \\
\hline Jejunum (whole size) & 26 \\
\hline Lung (whole size) & 35 \\
\hline Pancreas (whole size) & 26 \\
\hline Esophagus (whole size) & 35 \\
\hline Skeletal muscle (1 $\mathrm{cm}^{3}$ ) & 35 \\
\hline Trachea (whole size) & 26 \\
\hline Testis (whole size) & 26 \\
\hline
\end{tabular}

Tissues labeled with Hoechst 33342, were apparent after clearing with the FACT protocol in different depths (Figure 3).

\subsection{A link to classical histology with the FACT- cleared tissue histology}

Having shown that a antibody cell labeling is well compatible with the FACT method we wanted to test the quality of different tissues after clearing for two reasons: 1 ) to test the preservation of tissue and cell structure after clearing with FACT and 2) for the compatibility with medical histopathology, since histopathologists generally have experience in section evaluation that are prepared with classical histology. As shown in Figure 4, hematoxylin and eosin staining method worked for the FACT-cleared tissues nearly as well as for standard 4\% PFA fixed tissues used as controls. We performed the same protocol for other types of cleared tissue with FACT (Figure 5) without comparing with standard method.

\section{4 | DISCUSSION}

For the first time, we demonstrated the clearing of tissues of an avian species, Chukar partridges, with the FACT protocol for the effective clearing and imaging of immunostained tissues. Different tissues were cleared by FACT protocol with different speed. Various factors have effect on the speed of clearing of a tissue including size, fixation type and time, cellular content and age in a tissue, and fiber types of tissue (Liu et al., 2016). Modification of the FACT method (Xu et al., 2017) to the present method included alterations of immunolabelling and imaging to adapt this method for nonequipped laboratories. Removing of triton X100 or other similar perforator solutions from FACT solutions is the first modification has been done in the FACT method. As lipid cellular walls were removed in this protocol and there is no hydrogel, so applications of these chemicals that make holes for better penetration of antibodies were not logic. In comparison with the FACT protocol (Xu et al., 2017), we used Hoechst for labeling of nuclei and presented a protocol for this staining purpose. Our recent FACT approach has been developed in murine for labeling of vessels without staining (Khoradmehr, Mazaheri, Anvari, \& Tamadon, in press). Furthermore, using glycerol for $12 \mathrm{hr}$ did not solve Hoechst in comparison with FocusClear that is not compatible with DAPI staining of nucleus in CLARITY (Tomer et al., 2014).

Although the most important part of whole tissue clearing is optical sectioning for 3D imaging and this can be perfectly achieved by laser confocal imaging, availability of this expensive microscope is a big challenge for adapting the whole tissue imaging for traditional laboratory. Therefore, in the present study by the FACT method we used a z-stacked motorized stage fluorescent microscope for imaging of immunolabeled tissues. The $z$-stacked motorized stage facilitates imaging of depth of tissue layer by layer in the z-axis and automatically. Keep in mind, this approach has some limitations including the low working distance of available lens in fluorescent microscope in comparison with confocal microscope. This issue can be solved by cutting 1- to 2-mm piece of cleared tissue for imaging. Moreover, a lower penetration of fluorescent light in comparison with laser in 

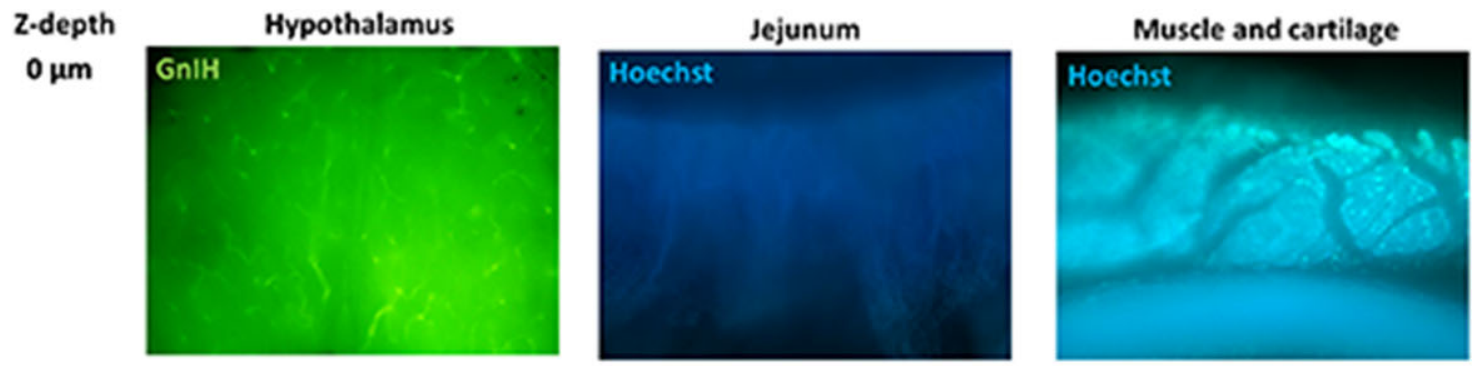

$50 \mu \mathrm{m}$
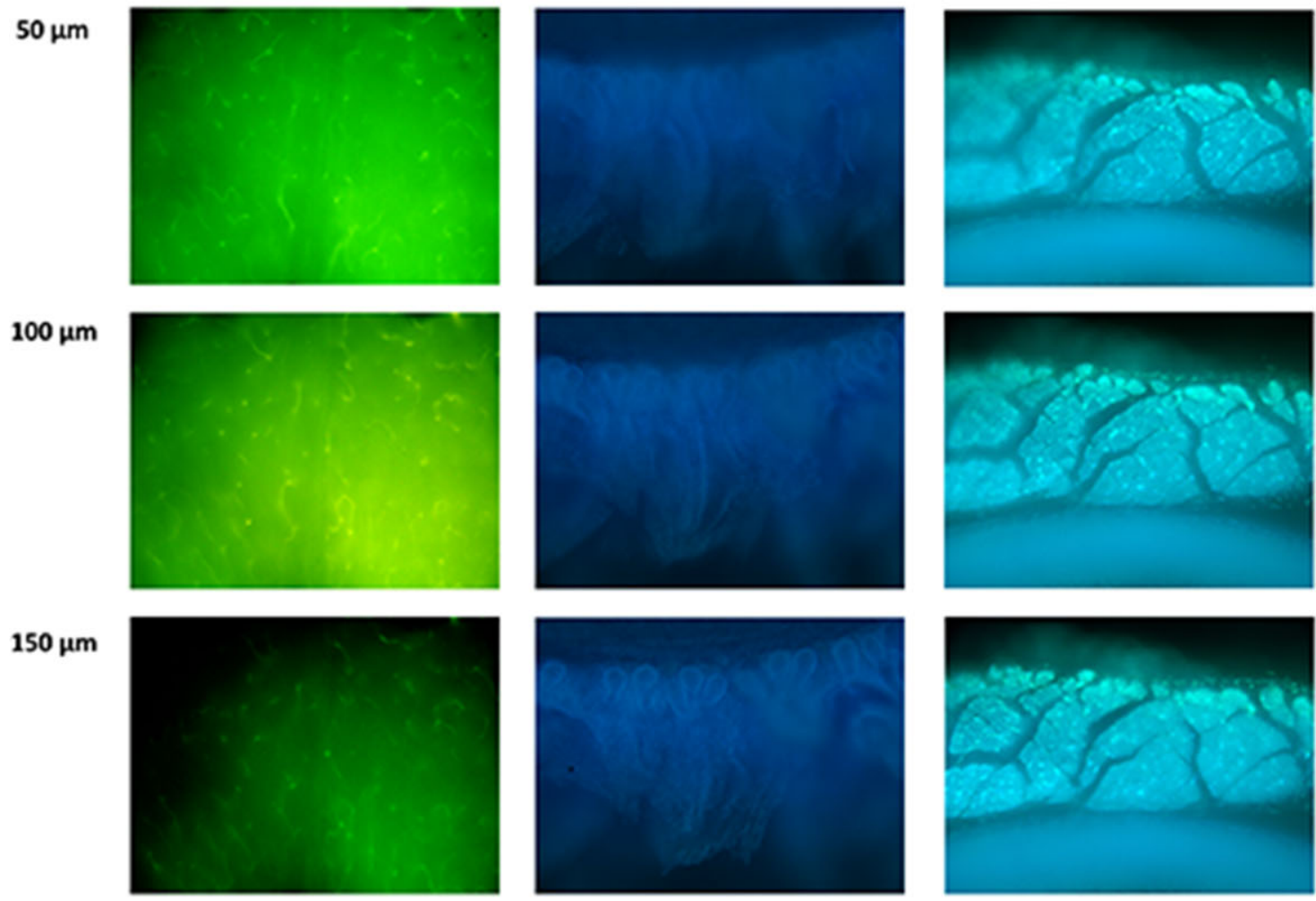

$200 \mu \mathrm{m}$
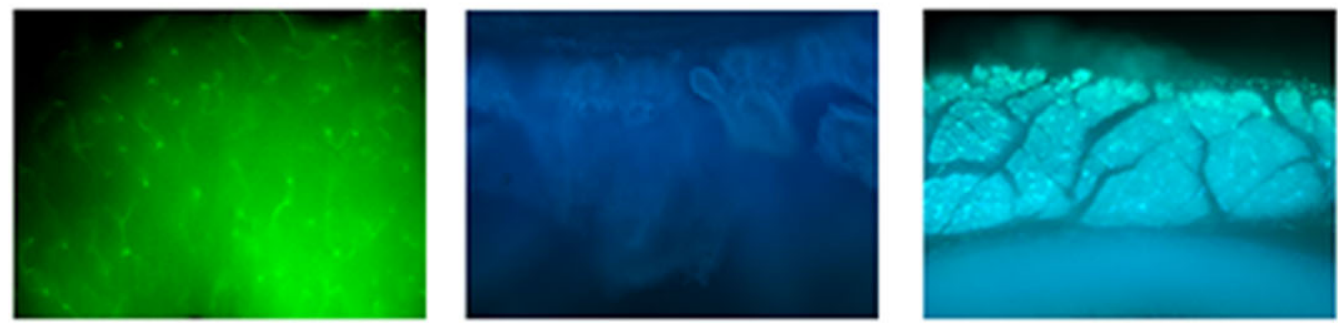

FIGURE 3 Different depths of the hypothalamus, jejunum and skeletal muscle of the partridge after clearing and imaging of tissues using fast free of acrylamide clearing tissue (FACT) [Color figure can be viewed at wileyonlinelibrary.com]

confocal, caused limitation of imaging of tissue for maximum depth of 200 to $250 \mu \mathrm{m}$.

Regarding to clearing time, avian brain slice clearing with the FACT protocol, as a passive clearing method of tissue, required 3 days for completion. Removing hydrogel decreased clearing time in comparison with hydrogel-based methods such as 4 days in the passive CLARITY (Tomer et al., 2014) and 4-9 days in the PACT (Yang et al., 2014) in mice. Furthermore, immunolabelling time decreased to 6 day in the FACT in comparison with 10 days in the passive CLARITY and PACT.

Evaluating the FACT on the classical histology method, our results further support a good retention of the tissue specimens so that different tissues remain distinguishable in classical histology with hematoxylin staining due to preserved morphology after the FACT protocol. Clearly, the time-consuming procedure of the FACT does not suggest this method for a daily routine procedure in pathologic labs. Our findings also close the gap between the novel phenotyping technologies of the FACT and the well-established conventional diagnostic histopathology.

\section{5 | CONCLUSIONS}

The FACT method is a simple technique which might be appropriate for laboratories in developing countries, lacking advanced microscopes such as confocal microscope. Successful labeling of neurons and nuclei in a bird species after clearing by the FACT approach resulted in 3D imaging of various tissues for the first time. These findings therefore 


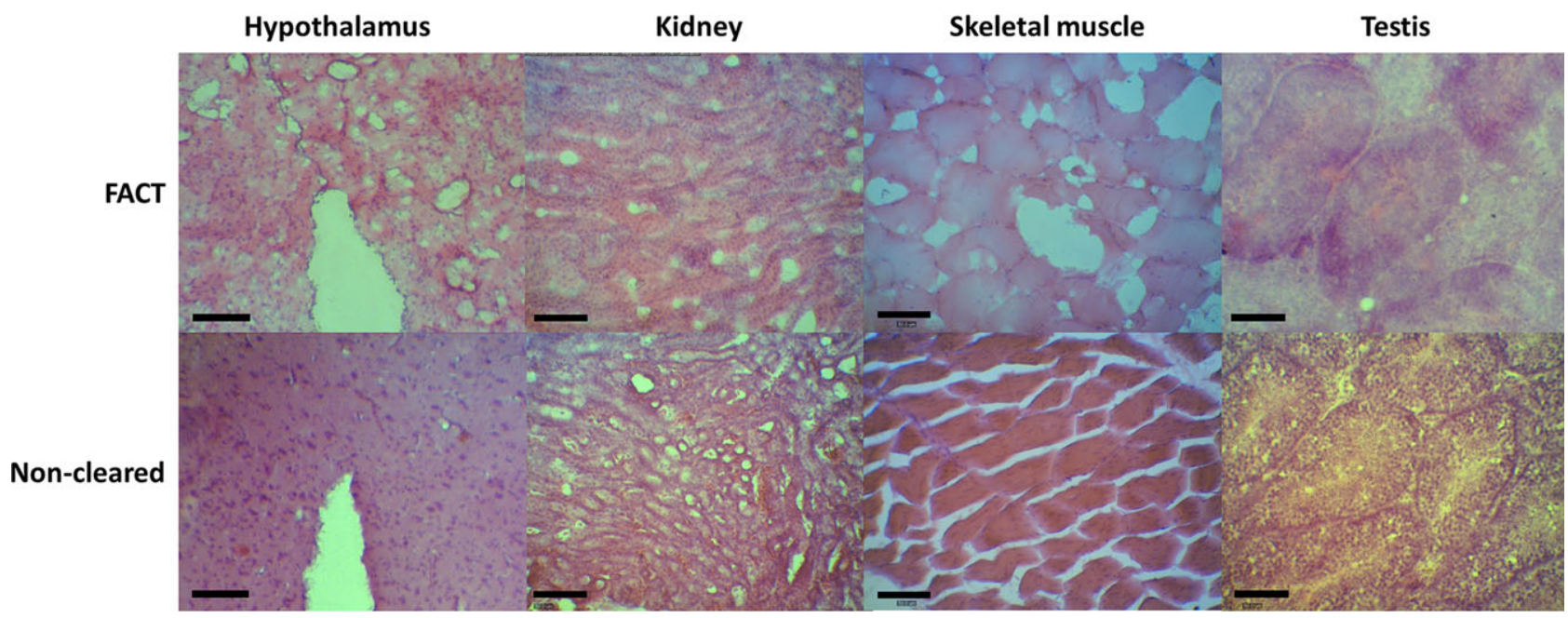

FIGURE 4 Comparison of different hematoxylin and eosin stained tissues after clearing with fast free of acrylamide clearing tissue (FACT) or without clearing in partridge (bars are $100 \mu \mathrm{m}$ ) [Color figure can be viewed at wileyonlinelibrary.com]
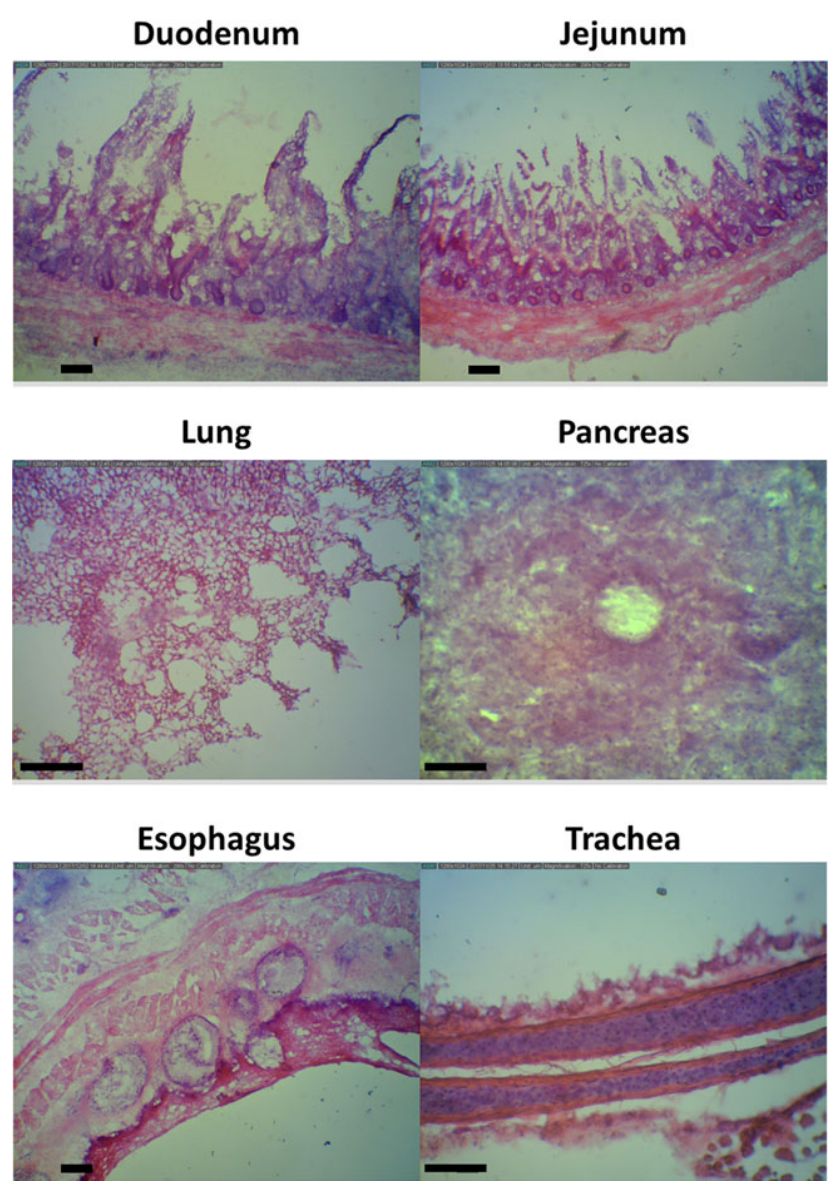

FIGURE 5 Different hematoxylin and eosin stained tissues after clearing with fast free of acrylamide clearing tissue (FACT) in partridge (bars are $100 \mu \mathrm{m}$ ) [Color figure can be viewed at wileyonlinelibrary.com]

enable histopathologists to use the FACT method to phenotype proteins and also apply their experience with classical histopathology.

\section{ACKNOWLEDGMENTS}

The authors are grateful to the College of Agriculture, Shiraz University and Central Research Laboratory, Shiraz University of Medical
Sciences for supporting this research. This study was financially supported with Department of Animal Science, College of Agriculture, Shiraz University.

\section{CONFLICT OF INTEREST}

The authors have declared that there is no conflict of interests.

\section{AUTHOR CONTRIBUTIONS}

A.T., M.R.J.S., F.R., F.M.R., S.S., M.R.N., M.D., N.T., A.A., A.N., A.A.M., and K.T. designed and performed the experiments, analyzed the data, and co-wrote the paper. A.T., F.R., F.M.R., S.S., M.R.N., A.A., M.R.J.S., and A.N. performed the tissue processing experiments. A.T., F.R., F.M.R., S.S., M.D., N.T., A.A.M., M.R.N., and K.T. performed the tissue staining and microscopic imaging. A.T., M.R.J.S., M.R.N., F.R., and K.T. designed the experiments, supervised the research, and co-wrote the paper.

\section{REFERENCES}

Adavi, H., Jafarzadeh Shirazi, M. R., Zamiri, M. J., Namavar, M. R., Tanideh, N., \& Tamadon, A. (2011). Effect of lactation on the expression of gonadotropin-inhibitory hormone in dorsomedial and paraventricular nuclei of the rat hypothalamus. Physiology and Pharmacology, 15(2), 164-172.

Asadi Yousefabad, S. L., Tamadon, A., Rahmanifar, F., Jafarzadeh, Shirazi, M. R., Sabet Sarvestani, F., ... Niazi, A. (2013). Lactation effect on mRNAs expression of RFRP-3 and KiSS-1 in dorsomedial and arcuate nuclei hypothalamus of rat. Physiology and Pharmacology, 17(3), 277-285.

Chowdhury, V. S., Tomonaga, S., Nishimura, S., Tabata, S., Cockrem, J. F., Tsutsui, K., \& Furuse, M. (2012). Hypothalamic gonadotropin-inhibitory hormone precursor mRNA is increased during depressed food intake in heat-exposed chicks. Comparative Biochemistry and Physiology Part A: Molecular \& Integrative Physiology, 162(3), 227-233.

Chung, K., Wallace, J., Kim, S.-Y., Kalyanasundaram, S., Andalman, A. S., Davidson, T. J., ... Denisin, A. K. (2013). Structural and molecular interrogation of intact biological systems. Nature, 497(7449), 332-337.

Dodt, H.-U., Leischner, U., Schierloh, A., Jährling, N., Mauch, C. P., Deininger, K., ... Becker, K. (2007). Ultramicroscopy: Three-dimensional 
visualization of neuronal networks in the whole mouse brain. Nature Methods, 4(4), 331.

Jafarzadeh Shirazi, M. R., Namavar, M. R., \& Tamadon, A. (2011a). Coexpression of gonadotropin inhibitory hormone and gonadotropin releasing hormone neurons in the preoptic area of hypothalamus in the phases of estrous cycle of the ewe. Journal of Iranian Anatomical Sciences, 9(34), 64-70.

Jafarzadeh, Shirazi, M. R., Namavar, M. R., \& Tamadon, A. (2011b). Expression of gonadotropin inhibitory hormone in the preoptic area and its relation with phases of estrous cycle of ewe. Physiology and Pharmacology, 15(1), 90-96.

Jafarzadeh, Shirazi, M. R., Tamadon, A., \& Namavar, M. R. (2011c). Coexpression of gonadotropin inhibitory hormone with Agouti-related peptide in the neurons of arcuate nucleus of ewe hypothalamus. Physiology and Pharmacology, 15(2), 201-209.

Jafarzadeh Shirazi, M. R., Pazoohi, F., Zamiri, M. J., Salehi, M. S. Namavar, M. R., Tamadon, A., ... Tsutsui, K. (2013). Expression of RFamide-related peptide in the dorsomedial nucleus of hypothalamus during the estrous cycle of rats. Physiology and Pharmacology, 17(1), 72-79.

Jafarzadeh Shirazi, M. R., Zamiri, M. J., Salehi, M. S., Moradi, S., Tamadon, A., Namavar, M. R., ... Caraty, A. (2014). Differential expression of RFamide-related peptide, a mammalian gonadotrophin-inhibitory hormone orthologue, and kisspeptin in the hypothalamus of Abadeh ecotype does during breeding and anoestrous seasons. Journal of Neuroendocrinology, 26(3), 186-194.

Jahanara, M., Tamadon, A., Jafarzadeh, Shirazi, M. R., Rahmanifar, F., Sabet, ... Niazi, A. (2014). Long term malnutrition and mRNAs expression of RFRP-3 and KiSS-1 in hypothalamus of female ovariectomized rats. Physiology and Pharmacology, 17(4), 370-378.

Karami Kheirabad, M., Ahmadloo, S., Namavar Jahromi, B., Rahmanifar, F., Tamadon, A., Ramezani, A., ... Koohi-Hosseinabadi, O. (2016). Alterations of hypothalamic RF-amide related peptide- 3 and Kiss1 gene expressions during spermatogenesis of rat in chronic stress conditions. Veterinarski Arhiv, 86(6), 841-856.

Khoradmehr, A., Mazaheri, F., Anvari, M., \& Tamadon, A. (in press). A simple technique for three-dimensional imaging and segmentation of brain vasculature using Fast Free-of-Acrylamide Clearing Tissue (FACT) in murine. Cell Journal.

Kuenzel, W. (2015). Chicken brain atlas. In E. D. Jarvis (Ed.), AvianBrain.org, A Resource for Brain Researchers. Durham, NC: Duke University.

Liu, A. K. L., Hurry, M. E. D., Ng, O. T.-W., DeFelice, J., Lai, H. M., Pearce, R. K. B., ... Gentleman, S. M. (2016). Bringing CLARITY to the human brain: Visualization of Lewy pathology in three dimensions. Neuropathology and Applied Neurobiology, 42(6), 573-587.

Liu, A. K. L., Lai, H. M., Chang, R. C., \& Gentleman, S. M. (2017). Free of acrylamide sodium dodecyl sulphate (SDS)-based tissue clearing (FASTClear): A novel protocol of tissue clearing for three-dimensional visualization of human brain tissues. Neuropathology and Applied Neurobiology, 43(4), 346-351.

Murray, E., Cho, J. H., Goodwin, D., Ku, T., Swaney, J., Kim, S.-Y., ... Hubbert, A. (2015). Simple, scalable proteomic imaging for high-dimensional profiling of intact systems. Cell, 163(6), 1500-1514.

Noroozi, A., Jafarzadeh Shirazi, M. R., Tamadon, A., Moghadam, A., \& Niazi, A. (2015). Increased litter size and suckling intensity stimulate mRNA of RFamide-related peptide in rats. International Journal of Fertility \& Sterility, 9(3), 380-386.
Rezazadeh, F. M., Shirazi, M. R. J., Zamiri, M. J., Salehi, M. S. Nama-Var, M. R., Akhlaghi, A., ... Tsutsui, K. (2017). Seasonal changes in hypothalamic gonadotropin inhibitory hormone expression in the paraventricular nucleus of chukar partridge (Alectoris chukar). Animal Reproduction, 14(2), 452-458.

Salehi, M. S., Jafarzadeh, Shirazi, M. R., Zamiri, M. J., Pazhoohi, F., Namavar, M. R., ... Zarei, A. (2013). Hypothalamic expression of KiSS-1 and RFamide-related peptide-3 mRNAs during the estrous cycle of rats. International Journal of Fertility \& Sterility, 6(4), 304-309.

Salehi, M. S., Tamadon, A., Jafarzadeh Shirazi, M. R., Namavar, M. R., \& Zamiri, M. J. (2015). The role of arginine-phenylalanine-amide-related peptides in mammalian reproduction. International Journal of Fertility \&Amp; Sterility, 9(3), 268-276.

Sarvestani, F. S., Tamadon, A., Koohi-Hosseinabadi, O., Nezhad, S. M., Rahmanifar, F., Shirazi, M. R. J., ... Niazi, A. (2014). Expression of RFamide-related peptide-3 (RFRP-3) mRNA in dorsomedial hypothalamic nucleus and KiSS-1 mRNA in arcuate nucleus of rat during pregnancy. International Journal of Fertility \& Sterility, 8(3), 333-340.

Shaaban, Z., Jafarzadeh Shirazi, M. R., Nooranizadeh, M. H., Tamadon, A., Rahmanifar, F., Ahmadloo, S., ... Koohi Hosseinabadi, O. (2018). Decreased expression of arginine-phenylalanine-amide-related peptide-3 gene in dorsomedial hypothalamic nucleus of constant light exposure model of polycystic ovarian syndrome. International Journal of Fertility \&Amp; Sterility, 12(1), 43-50.

Tomer, R., Ye, L., Hsueh, B., \& Deisseroth, K. (2014). Advanced CLARITY for rapid and high-resolution imaging of intact tissues. Nature Protocols, 9(7), 1682.

Tsutsui, K., Bentley, G. E., Bedecarrats, G., Osugi, T., Ubuka, T., \& Kriegsfeld, L. J. (2010). Gonadotropin-inhibitory hormone (GnlH) and its control of central and peripheral reproductive function. Frontiers in Neuroendocrinology, 31(3), 284-295.

Tsutsui, K., Saigoh, E., Ukena, K., Teranishi, H., Fujisawa, Y., Kikuchi, M., ... Sharp, P. J. (2000). A novel avian hypothalamic peptide inhibiting gonadotropin release. Biochemical and Biophysical Research Communications, 275(2), 661-667.

Tsutsui, K., Ubuka, T., Bentley, G. E., \& Kriegsfeld, L. J. (2013). Review: Regulatory mechanisms of gonadotropin-inhibitory hormone $(\mathrm{GnlH})$ synthesis and release in photoperiodic animals. Frontiers in Neuroscience, 7, 60.

Xu, N., Tamadon, A., Liu, Y., Ma, T., Leak, R. K., Chen, J., ... Feng, Y. (2017). Fast free-of-acrylamide clearing tissue (FACT): An optimized new protocol for rapid, high-resolution imaging of three-dimensional brain tissue. Scientific Reports, 7(1), 9895.

Yang, B., Treweek, J. B., Kulkarni, R. P., Deverman, B. E., Chen, C.-K., Lubeck, E., ... Gradinaru, V. (2014). Single-cell phenotyping within transparent intact tissue through whole-body clearing. Cell, 158(4), 945-958.

How to cite this article: Mohammad Rezazadeh F, Saedi S, Rahmanifar $F$, et al. Fast free of acrylamide clearing tissue (FACT) for clearing, immunolabelling and three-dimensional imaging of partridge tissues. Microsc Res Tech. 2018;1-9. https://doi.org/10.1002/jemt.23078 